\title{
THE EFFECT OF DIAZEPAM ON THE RESPIRATORY RESPONSE TO CARBON DIOXIDE*
}

\author{
Stephen N. Stgen, SC. D., M.D., Stanley W. Weitziner, M.D., $\nmid$ \\ Ketsuke Amaka, M.D. and Leonardo R. Martinez, M.D.
}

Diazepam (Valium is a derivative of $-1,4$, benzodiazepine. The first tranquilizer of this series was chlordiazepoxide (Librium $\left.{ }^{(}\right)$). Recent reports of the use of diazepam for preoperative sedation have indicated that the drug has the property of reducing anxiety without depressing circulation and respiration. ${ }^{1-4}$ Since the effect of diazepam on respiration has not been fully investigated, we have submitted it to quantitative assessment employing a modification of the rebreathing $\mathrm{CO}_{2}$-challenge technique of Eckenhoff, 6 which we have used for this purpose in previous studies. ${ }^{6}$

\section{Methods and Materuals}

A 9-liter Collins spirometer was used to calibrate a Wedge Spirometer. The subject inhaled oxygen from and exhaled into the latter spirometer, which was initially filled with approximately 7 litres of oxygen. The endogenously produced $\mathrm{CO}_{2}$ accumulated since there was no $\mathrm{CO}_{2}$-absorber in this circuit.

The $\mathrm{CO}_{2}$ concentration was monitored, the gas being sampled from the mouthpiece and returned to the bellows of the Wedge Spirometer. This spirometer produced an electrical voltage proportional to the tidal volume. $\mathrm{CO}_{2}$ mixtures in $\mathrm{O}_{2}$, whose concentrations were known to the second decimal place, were used for calibrating a $\mathrm{CO}_{2}$ analyser. . Both the tidal volumes and the $\mathrm{CO}_{2}$ concentrations were continuously recorded on a direct-writing multi-channel recorder (Figure 1).

Six healthy female volunteers underwent the tests. To ensure comparable drug response times, the intravenous route of administration was chosen.

Diazepam was used at dose levels of $0.025 \mathrm{mg} . / \mathrm{kg}$. (I subject), $0.04 \mathrm{mg} . / \mathrm{kg}$. ( 3 subjects), and $0.66 \mathrm{mg}, / \mathrm{kg}$. ( 4 subjects). Meperidine was given at a dose level of $0.5 \mathrm{mg} . / \mathrm{kg}$. ( 6 subjects) for comparison.

End-expiratory $\mathrm{P}_{\mathrm{CO}_{2}}\left(\mathrm{P}_{\mathrm{ECO}}\right)$ was plotted against alveolar ventilation adjusted to BTPS and corrected for changes in dead space with hyperventilation ${ }^{7}$ for each minute of the run. The line that best fitted the third, fourth, and fifth minute values of alveolar ventilation was drawn. An alveolar ventilation ratio

\footnotetext{
- Presented in part at the 159th Annual Convention of the Medical Society of New York, Section on Anesthesia, New York City, February 15, 1965. The authors are from the Department of Anesthesiology, State University of New York Downstate Medical Center and Kings County Hospital Center, Brooklyn, New York, U.S.A.

$\nmid$ Recipient of U.S.P.H.S. Research Career Development Award NB-K-17652.

¥Present address: Karolinska Hospital, Thoracic Clinic, Stockholm, Sweden.

\$Model 170, Med-Science Electronics, St. Louis, Missouri.

†Model LB-1, Beckman Instruments, Palo Alto, California.
} 


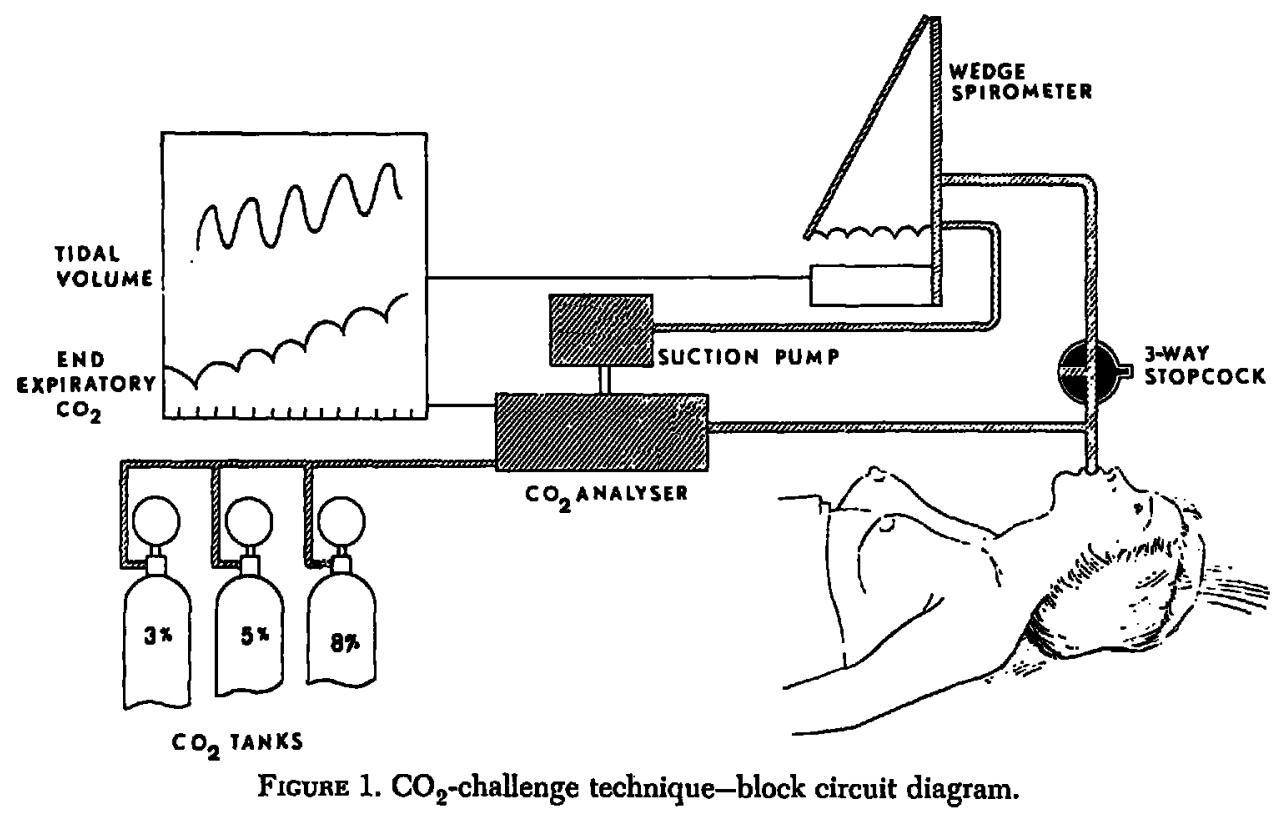

$\left(V_{\Delta} R\right)$ which is 2.5 times the averaged pre-drug alveolar ventilation for the first minute was then used to intercept each of these lines. The intercept of the control period response curve was subtracted from the intercepts of the post-drug response curves. These values are indicative of shifts in the ventilatory response curves from the control period response curve. A positive sign is given for displacement to the right and indicates respiratory depression. A negative sign (displacement to the left) represents respiratory stimulation. ${ }^{6}$

Each challenge lasted 5 minutes or longer. These challenges were repeated at varying intervals up to 4 hours after injection of the drug unless the results indicated a return of ventilatory response to pre-drug levels. Values of approximately $55 \mathrm{~mm}$. $\mathrm{Hg}$, equivalent to about 8 per cent $\mathrm{CO}_{2}$, were measured during the last minute of the runs. The minimum interval between successive tests on any one subject was three days.

\section{Discussion of Results}

This technique of the $\mathrm{CO}_{2}$-challenge method was chosen because it permitted continuous recording of increasing $\mathrm{P}_{\mathrm{CO}_{2}}$ levels in the body with minimal discomfort on the part of an awake subject.

The average displacement of $\mathrm{P}_{\mathrm{ECO}_{2}}$ was approximately $+8 \mathrm{~mm} . \mathrm{Hg}$ at the 20-minute test period after injection of meperidine.

For diazepam, the average displacement of $\mathrm{P}_{\mathrm{EcO}}$ was never greater than $+3.5 \mathrm{~mm}$. Hg at any test period-even at the highest dose level. The displacement values at each time interval after drug injection were averaged. These data were subjected to statistical analysis using Student's $t$ Test.

Determination of statistical significance within 97.5 per cent confidence limits indicated that diazepam produced no detectable respiratory depression at dose levels up to $0.066 \mathrm{mg} . / \mathrm{kg}$; whereas a dose of $0.5 \mathrm{mg} . / \mathrm{kg}$. meperidine 
resulted in depression of the respiratory response to carbon dioxide up to one hour after drug injection (Table I).

TABLE I

Displacement (in mim. Hg $\mathrm{P}_{\mathrm{e} \mathrm{CO}_{2}}$ ) of Respiratory Stimulus Response Curves

\begin{tabular}{|c|c|c|c|c|c|c|}
\hline & Min. & 20 & 60 & 120 & 180 & 240 \\
\hline $\begin{array}{l}\text { Diazepam* } \\
(0.04 \mathrm{mg} . / \mathrm{kg} .) \\
(0.06 \mathrm{mg} . / \mathrm{kg} .)\end{array}$ & $\begin{array}{l}\text { Mean } \\
\pm \text { S.D. } \\
\text { Mean } \\
\pm \text { S.D. }\end{array}$ & $\begin{array}{l}0.2 \\
0.2 \\
2.0 \\
3.9\end{array}$ & $\begin{array}{l}3.2 \\
4.6 \\
3.5 \\
4.2\end{array}$ & $\begin{array}{l}2.8 \\
1.9 \\
3.3 \\
7.4\end{array}$ & $\frac{0.9 \dagger}{3.1 \dagger}$ & $\frac{3.2+}{=}$ \\
\hline $\begin{array}{l}\text { Meperidine } \\
(0.5 \mathrm{mg} . / \mathrm{kg} .)\end{array}$ & $\begin{array}{l}\text { Mean } \\
\pm \text { S.D. }\end{array}$ & $\begin{array}{l}8.2 \ddagger \\
4.4\end{array}$ & $\begin{array}{l}7.8 \ddagger \\
5.3\end{array}$ & $\begin{array}{l}6.3 \\
5.4\end{array}$ & $\begin{array}{l}3.2 \\
3.7\end{array}$ & - \\
\hline
\end{tabular}

*0.025 mg./kg. (1 subject) not included.

$\dagger 2$ subjects.

†Significantly decreased $(p<0.025)$ from pre-drug.

\section{Summary and Conclusions}

Six healthy adult female volunteers were used in the quantitative assessment of their respiratory responses following intravenous administration of meperidine and diazepam. A modified rebreathing $\mathrm{CO}_{2}$-challenge technique of Eckenhoff et al., ${ }^{5}$ previously reported, ${ }^{6}$ was used for this purpose.

The $\mathrm{CO}_{2}$ stimulus response curves obtained confirmed the respiratory depressant response following the use of $0.5 \mathrm{mg} . / \mathrm{kg}$. meperidine. Diazepam, at dose levels up to $0.066 \mathrm{mg} . / \mathrm{kg}$., produced no statistically significant respiratory response to carbon dioxide detectable by this method ( $p<0.025)$.

\section{RÉSUMÉ}

Six adultes volontaires du sexe féminin et en bonne santé ont servi à l'évaluation quantitative des réactions respiratoires à la suite d'injection intraveineuse de mépéridine et de diazepam. On a utilisé à cet effet une technique modifiée de Eckenhoff et coll., décrite antérieurement.

La courbe des réponses obtenues par la stimulation du $\mathrm{CO}_{2}$ a confirmé que l'usage de $0.5 \mathrm{mg} . / \mathrm{kg}$. de mépéridine produissait une dépression respiratoire. Le diazepam, ¿ la dose de $0.066 \mathrm{mg} . / \mathrm{kg}$., n'a pas produit de réponse de valeur statistique a la stimulation du $\mathrm{CO}_{2}$ en employant cette méthode $(p<0.025)$.

\section{ACKNOWLEDGMENT}

These studies were supported in part by a grant from Hoffmann-La Roche, Inc., Nutley, N.J.

\section{REFERENCES}

1. Campan, L. \& Espacno, M.-Th. Note sur le diazépam en anesthésiologie. Ann. Anesth. Franc. V: 711 (1964).

2. Goto, H.; Yodo, M.; Mru, H.; \& Hatano, S. Clinical Experience of Diazepam as Premedication. Jap. J. Anesth. 14: 420 (1965). 
3. Brandt, A. L. \& OAkes, F. D. Preanesthetic Medication: Double-Blind Study of a New Drug, Diazepam. Anesth. \& Analg. 44: 125 (1965).

4. Tornetra, F. J. Diazepam as a Preanesthetic Medication: A Double-Blind Study. Anesth. \& Analg. 44: 449 (1965).

5. Eckenhoff, J. E.; Hetruch, M.; \& Hege, M. J. D. A Method for Studying Respiratory Functions in Awake or Anesthetized Patients. Anesthesiology 17: 66 (1956).

6. Steen, S. N.; Amahi, K.; \& Martinez, L. R. The Effect of Oxazepam on the Respiratory Response to Carbon Dioxide. Anesth. \& Analg. To be published (1966).

7. GraY, I. S.; Grodins, F. S.; \& Carter, E. T. Alveolar and Tidal Ventilation and Deadspace Problem. J. Appl. Physiol. 9: 307 (1956). 